\title{
Aggregate Information and the Role of Monetary Policy in an Open Economy
}

\section{Kent P. Kimbrough}

Duke University

A model of a small open economy in which agents trade in local goods markets and an economy-wide asset market is developed. Purchasing-power parity is assumed to hold at the aggregate level. However, because of local deviations from purchasing-power parity, agents possess differential information. Using this framework, it is shown that when the exchange rate is flexible monetary policy can influence the distribution of real output by altering the information content of the exchange rate. However, when monetary policy is committed to fixing the exchange rate (by a feedback rule) the distribution of real output is independent of the particular exchange rate rule chosen. The stability of real output under the two regimes is compared, and it is demonstrated that regardless of the stability of domestic monetary policy a flexible exchange rate regime is superior in this respect. Possible qualifications and extensions of these results are also discussed.

The policy implications of the new classical macroeconomics have attracted considerable attention. The most controversial result has been the policy-ineffectiveness proposition advanced by Sargent and Wallace (1975). Recently papers by Weiss (1980, 1982) and King (1982) have demonstrated that this policy-ineffectiveness proposition breaks down if agents with differential information transact in a common market and thus have access to a common price. Their

I would like to thank Grant Gardner, George Tauchen, and two anonymous referees for their helpful comments. See King (1983) for a closed-economy treatment of closely related issues. King's paper came to my attention at too late a stage to be incorporated into the body of the paper. 
arguments hinge on the ability of monetary policy to influence the information content of prices that serve to aggregate the diverse information of market participants. The aim of this paper is to extend to the open economy some of these ideas and policy implications that have recently emerged from the literature on the new classical macroeconomics.

The model employed in the paper, and developed in Section I, is an open-economy version of the "island" paradigm popularized by Lucas $(1972,1973)$, which is intended to capture the essential elements of the incomplete information view of the business cycle advanced by Friedman (1968) and Phelps (1970). Agents trade in spatially separated goods markets, with prices differing across markets because agents in each market choose different foreign trading partners at the start of each period. Purchasing-power parity holds at the aggregate level, but there are local (market-specific) deviations. In addition, agents also trade in integrated asset markets and thus have access to common price information, in particular the exchange rate and foreign interest rate. The incorporation of an economy-wide asset market into the model makes it similar in spirit to Barro (1980). ${ }^{1}$ Since agents with diverse information are trading in a common market, the framework is well suited for discussing the policy-ineffectiveness proposition and when it may break down. This discussion is the subject of Sections II-IV. Sections II and III below examine the determination of equilibrium and the role of monetary policy under a flexible exchange rate regime. Section IV examines the role of exchange rate policy under a fixed exchange rate regime. Finally, Section $\mathrm{V}$ contrasts the role of macroeconomic policy under fixed and flexible exchange rate regimes and compares the amplitude of the business cycle under the two regimes. Possible qualifications and extensions are also discussed.

Before proceeding, it will be useful to summarize briefly the main conclusions of the paper. First, it is demonstrated that under flexible exchange rates systematic monetary policy can influence the distribution of real output by altering the information content of the exchange rate. This is an open-economy extension of the results derived by Weiss $(1980,1982)$ and King (1982). Second, under fixed exchange rates the monetary authorities cannot use exchange rate policy to influence the distribution of real output, because exchange rates fail to convey useful information. Third, it is shown that for a small open economy flexible exchange rates are superior to fixed exchange rates, in the sense that they result in a smaller variance of real output

\footnotetext{
${ }^{1}$ Harris and Purvis (1981) use a model similar to the one developed here to examine exchange rate behavior and market efficiency.
} 
about its full current information value, regardless of the wisdom or discipline with which monetary policy is conducted.

\section{The Model}

The country under consideration is assumed to be a small open economy. One good is produced and consumed by domestic agents who are located in spatially separated markets indexed by the letter $z$; there is no trade in goods across markets at a point in time. The distinguishing characteristic of each market is its choice of a foreign trading partner at the start of each period. Because different domestic markets have different foreign trading partners, commodity prices differ from market to market as specified below. However, at the aggregate level purchasing-power parity holds-deviations from purchasing-power parity are strictly localized and uncorrelated over time. The only assets domestic agents are assumed to hold are domestic money and foreign bonds. Asset markets are integrated so that agents in all markets observe the nominal interest rate on foreign bonds, $i^{*}$, and the (natural logarithm of the) exchange rate, $S_{t}$, defined as the price of foreign exchange in terms of domestic currency. Agents in market $z$ also know (the natural logarithm of) their local commodity prices measured in home and foreign currencies, $P_{t}(z)$ and $P_{t}^{*}(z)$.

The formal structure of the model is summarized by the following (all variables are in natural logarithms except for $i^{*}$ and $i_{t}$, which are in levels):

$$
\begin{gathered}
P_{t}(z)=S_{t}+P_{t}^{*}(z), \\
P_{t}^{*}(z)=P_{t}^{*}+z_{t}, \\
P_{t}^{*}=P_{t-1}^{*}+v_{t}, \\
y_{t}(z)=\alpha r_{t}(z)+u_{t} ; r_{t}(z)=P_{t}^{*}(z)-E_{z} P_{t+1}^{*}+i^{*}, \\
M_{t}^{d}=P_{t}+\phi y_{t}-\lambda i_{t}+w_{t} .
\end{gathered}
$$

Expression (1) is a goods-market arbitrage condition for market $z$. As shown by (2), goods prices in the local community's foreign trading partner, $P_{t}^{*}(z)$, deviate from the economy-wide average foreign price, $P_{t}^{*}$, by an amount $z_{t}$, where $z_{t} \sim N\left(0, \sigma_{z}^{2}\right)$. Foreign prices differ across markets because the foreign country is also assumed to consist of a set of local markets. Since the home country is small, domestic agents take foreign prices and their distribution as given. If (1) and (2) are combined, it can be seen that $P_{t}(z)=S_{t}+P_{t}^{*}+z_{t}$, which implies that the economy-wide average of local commodity prices (the price level) is $P_{t}=S_{t}+P_{t}^{*}$. Therefore, purchasing-power parity holds at the aggregate level, but there are local deviations reflected by $z_{t}$. As 
shown by (3), it is assumed for simplicity that the stochastic structure of the foreign economy is such that the economy-wide average foreign price follows a random walk with $v_{t} \sim N\left(0, \sigma_{v}^{2}\right)$.

The local commodity supply function (4) captures the intertemporal aspects of the model. An increase in the real rate of return, or relative price of current goods in terms of future goods, perceived by agents in market $z, r_{t}(z)$, causes them to substitute future for current leisure and thus results in an increase in current real output, $y_{t}(z)$. The relative price term can be explained as follows: a sale this period allows agents to accumulate $P_{t}^{*}(z)$ plus the nominal rate of return on foreign bonds by period $t+1$, while a sale next period is expected to yield $E_{z} P_{t+1}^{*}$, which is the expected future foreign price conditioned on the information available to agents in market $z$. Comparison of these yields results in the relative price term $P_{t}^{*}(z)-E_{z} P_{t+1}^{*}+i^{*}$. Real output is also influenced by an aggregate supply shock, $u_{t}$, which is normally and independently distributed with mean zero and variance $\sigma_{u}^{2}$.

The aggregate demand for money, $M_{t}^{d}$, is given by (5) and depends on the economy-wide average levels of local prices, real output, and the perceived opportunity cost of holding money, which are given by $P_{t}, y_{t}$, and $i_{t}$. In addition, there is also an aggregate money demand shock, $w_{t} \sim N\left(0, \sigma_{w}^{2}\right)$. This specification follows from the fact that asset markets are integrated and can be viewed as having been obtained by averaging local money demand functions of the same form across markets. The opportunity cost of holding money as perceived by agents in market $z$ is the forgone interest earnings on the foreign bond plus the expected rate of depreciation of the domestic currency, $E_{z} S_{t+1}-S_{t}$. Averaging this opportunity cost across markets implies that

$$
i_{t}=i^{*}+\left(\overline{E_{z} S_{t+1}}-S_{t}\right),
$$

where $\overline{E_{z} S_{t+1}}$ is the economy-wide average of local expectations concerning the future exchange rate, $E_{z} S_{t+1}$.

\section{Flexible Exchange Rates and Full Current Information}

Under a flexible exchange rate regime the domestic money supply is a policy variable that is determined by the monetary authorities, and the exchange rate adjusts to maintain asset market equilibrium. In this and the following section the money supply, $M_{t}$, is assumed to be governed by the rule

$$
M_{t}=M_{t-1}+m_{t}+\psi v_{t-1},
$$


where $\psi$ is a policy parameter chosen by the monetary authorities, and the nonsystematic element of monetary policy, $m_{t}$, is assumed normally and independently distributed with mean zero and variance $\sigma_{m}^{2}$. The policy rule (7) can easily be altered to allow for a response to other lagged shocks without affecting any of the paper's qualitative conclusions.

\section{A. Solution Technique}

The most straightforward way to solve for the equilibrium under flexible exchange rates is to aggregate and then use the method of undetermined coefficients to solve for the equilibrium exchange rate.

Substitution of (1)-(3) into the relative price term, $r_{t}(z)$, yields

$$
r_{t}(z)=i^{*}+z_{t}+\left(v_{t}-E_{z} v_{t}\right)
$$

Using (8) in connection with the local supply function (4) when averaging across markets gives an expression for aggregate real output, $y_{t}$. When the resulting expression for aggregate real output is combined with (5)-(7) and the expression for the price level, $P_{t}$, that emerges from (1)-(3), it can be shown that asset market equilibrium requires

$$
\begin{aligned}
(1+\lambda) S_{t}= & M_{t-1}+m_{t}+\psi v_{t-1}-P_{t-1}^{*}-(1+\phi \alpha) v_{t}-\phi u_{t}-w_{t} \\
& +(\lambda-\phi \alpha) i^{*}+\phi \alpha \overline{E_{z} v_{t}}+\lambda \overline{E_{z} S_{t+1}},
\end{aligned}
$$

where $\overline{E_{z} v_{t}}$ is the economy-wide average of $E_{z} v_{t}$.

Applying the method of undetermined coefficients amounts to "guessing" a solution for the equilibrium exchange rate of the form ${ }^{2}$

$$
\begin{aligned}
S_{t}= & \pi_{0}+\pi_{1} M_{t-1}+\pi_{2} P_{t-1}^{*}+\pi_{3} v_{t-1} \\
& +\pi_{4} m_{t}+\pi_{5} v_{t}+\pi_{6} u_{t}+\pi_{7} w_{t} .
\end{aligned}
$$

The assumption of rational expectations requires that the expected future exchange rate be found by updating (10) one period and taking expectations conditional on all available information (which depends on the market in which an agent is currently located). With (7) and (9) this procedure yields

$$
\begin{aligned}
E_{z} S_{t+1}= & \pi_{0}+\pi_{1}\left(M_{t-1}+E_{z} m_{t}+\psi v_{t-1}\right) \\
& +\pi_{2}\left(P_{t-1}^{*}+E_{z} v_{t}\right)+\pi_{3} E_{z} v_{t}
\end{aligned}
$$

\footnotetext{
2 Note that local deviations from purchasing-power parity do not influence the exchange rate, since it is determined in an economy-wide asset market.
} 
Finally, the $\pi$ coefficients can be found from (9), (10), and the economy-wide average of (11).

\section{B. Equilibrium with Full Current Information}

When agents possess full current information, $E_{z} m_{t}=m_{t}$ and $E_{z} v_{t}=$ $v_{t}$. From (11) this can be seen to imply that $E_{z} S_{t+1}=\overline{E_{z} S_{t+1}}$. With these facts, solutions for the full current information $\pi$ 's (denoted by a tilde) can be obtained. These solutions are $\tilde{\pi}_{0}=(\lambda-\phi \alpha) i^{*}, \tilde{\pi}_{1}=\tilde{\pi}_{4}$ $=1, \tilde{\pi}_{2}=-1, \tilde{\pi}_{3}=\psi, \tilde{\pi}_{5}=-1+[\lambda \psi /(1+\lambda)], \tilde{\pi}_{6}=-\phi /(1+\lambda)$, and $\tilde{\pi}_{7}=-1 /(1+\lambda)$.

Regarding the real equilibrium of the economy, it can be seen from (8) that under full current information the real rate of return perceived by agents in market $z$ is

$$
\tilde{r}_{t}(z)=i^{*}+z_{t}
$$

With this in (4), it follows that the full current information level of real output in market $z$ is

$$
\tilde{y}_{t}(z)=\alpha\left(i^{*}+z_{t}\right)+u_{t} .
$$

As can be seen from this expression, a positive value of $z_{t}$ causes agents in market $z$ to increase their real output relative to the aggregate level, $\tilde{y}_{t}=\alpha i^{*}+u_{t}$. The reason for this is that agents in market $z$ are aware that the real rate of return in their market is unusually high, and in order to take advantage of this opportunity they substitute future for current leisure. This expansion in current labor supply results in an increase in real output in market $z$.

\section{Flexible Exchange Rates and Incomplete Information}

In the previous section the benchmark case of full current information was considered. In this section it is assumed that agents must use the market prices they observe to make inferences about the state of the economy. These prices will not, in general, perfectly reveal the state of the economy, and agents will thus have to make their supply and demand decisions on the basis of incomplete information. Equations (8)-(11) of Section II $A$ continue to hold in this instance. The main difference is that in solving the model $E_{z} m_{t}$ and $E_{z} v_{t}$ cannot simply be replaced by their actual values as under full current information. 


\section{A. Extracting Information from Prices}

In the model employed here agents observe four market prices-the nominal interest rate on foreign bonds and the exchange rate, both economy-wide prices, and their own local commodity prices, $P_{t}(z)$ and $P_{t}^{*}(z)$. Only two of these prices, the exchange rate and the local foreign currency commodity price, are useful to agents in their attempt to assess current economic conditions. This follows from the fact that, in the interest of parsimony, the nominal interest rate on foreign bonds is assumed to be uncorrelated with any contemporaneous shocks and that $P_{t}(z)$ is redundant given the arbitrage condition (1). ${ }^{3}$

The problem confronting agents is to use the information at their disposal to form conditional expectations of the current shocks. Equation (10) indicates that the information content of the exchange rate is $\pi_{4} m_{t}+\pi_{5} v_{t}+\pi_{6} u_{t}+\pi_{7} w_{t}$, and from (2) and (3) it follows that the information content of $P_{t}^{*}(z)$ is $v_{t}+z_{t}$. From (11) it can be seen that a solution to the model requires explicit calculation of $E_{z} m_{t}$ and $E_{z} v_{t}$ only. These expectations are given by

$$
\begin{aligned}
& E_{z} m_{t}=\theta_{1}\left(\pi_{4} m_{t}+\pi_{5} v_{t}+\pi_{6} u_{t}+\pi_{7} w_{t}\right)+\theta_{2}\left(v_{t}+z_{t}\right), \\
& E_{z} v_{t}=\beta_{1}\left(\pi_{4} m_{t}+\pi_{5} v_{t}+\pi_{6} u_{t}+\pi_{7} w_{t}\right)+\beta_{2}\left(v_{t}+z_{t}\right),
\end{aligned}
$$

where

$$
\begin{gathered}
\theta_{1}=\frac{\pi_{4} \sigma_{m}^{2}\left(\sigma_{v}^{2}+\sigma_{z}^{2}\right)}{\Delta}, \quad \theta_{2}=\frac{-\pi_{4} \pi_{5} \sigma_{m}^{2} \sigma_{v}^{2}}{\Delta} \\
\beta_{1}=\frac{\pi_{5} \sigma_{z}^{2} \sigma_{z}^{2}}{\Delta}, \quad \beta_{2}=\frac{\sigma_{v}^{2}\left(\pi_{4}^{2} \sigma_{m}^{2}+\pi_{6}^{2} \sigma_{u}^{2}+\pi_{7}^{2} \sigma_{w}^{2}\right)}{\Delta},
\end{gathered}
$$

and

$$
\Delta=\left(\boldsymbol{\sigma}_{v}^{2}+\boldsymbol{\sigma}_{z}^{2}\right)\left(\pi_{4}^{2} \boldsymbol{\sigma}_{m}^{2}+\pi_{6}^{2} \boldsymbol{\sigma}_{u}^{2}+\pi_{7}^{2} \boldsymbol{\sigma}_{w}^{2}\right)+\pi_{5}^{2} \boldsymbol{\sigma}_{z}^{2} \boldsymbol{\sigma}_{z}^{2}>0 .
$$

\section{B. Equilibrium with Incomplete Information}

The first step in providing a complete solution to the model would be to use the method of undetermined coefficients to solve for the $\pi$ 's, $\theta$ 's, and $\beta$ 's. However, this paper is concerned primarily with the behavior of real variables, and it turns out that quite a few conclusions can be drawn without solving explicitly for these coefficients. ${ }^{4}$ For the

\footnotetext{
${ }^{3}$ It would be possible, without altering any conclusions, to extend the model to allow for the foreign nominal interest rate to be correlated with current shocks, and in particular those influencing economy-wide foreign prices. This could be done along the lines of Flood and Marion (1982).

${ }^{4}$ About the best that can be done in this respect is to substitute out for the $\theta$ 's and $\beta$ 's
} 
discussion that follows it is sufficient to note that $\pi_{i}=\pi_{i}$ for $i=0$, ..., 3, since agents continue to know the economy's past history.

In order to examine the real equilibrium, it is convenient to solve the model in terms of the deviations of the incomplete information values of local relative prices and real outputs from their full current information values. From (8) and (12) it can be seen that

$$
r_{t}(z)-\tilde{r}_{t}(z)=v_{t}-E_{z} v_{t},
$$

and from (4) it follows that

$$
y_{t}(z)-\tilde{y}_{t}(z)=\alpha\left(v_{t}-E_{z} v_{t}\right) .
$$

Therefore, deviations of real variables from their full current information values arise solely from the errors agents make in predicting the economy-wide element of the contemporaneous foreign price shock, $v_{t}$. Since agents observe $P_{t}^{*}(z)=v_{t}+z_{t}$, expectational consistency requires that $E_{z} v_{t}+E_{z} z_{t}=v_{t}+z_{t}$, which implies that $v_{t}-E_{z} v_{t}=$ $E_{z} z_{t}-z_{t}$. Hence if agents in market $z$ underestimate the economywide component of the foreign price shock, they will overestimate the local component by the same amount and mistakenly perceive the local real rate of return to be unusually high, as indicated by (16). This will cause agents to increase their current labor supply and cause real output to exceed its full current information value, as shown by (17). A similar story can be told if agents overestimate the economywide component of the foreign price shock.

In order to determine how agents respond to various current shocks, note from (15) that

$$
v_{t}-E_{z} v_{t}=\left(1-\beta_{1} \pi_{5}-\beta_{2}\right) v_{t}-\beta_{1}\left(\pi_{4} m_{t}+\pi_{6} u_{t}+\pi_{7} w_{t}\right)-\beta_{2} z_{t} .
$$

It can be shown from the expressions for $\beta_{1}$ and $\beta_{2}$ presented earlier and from the fact that $\pi_{5}=-\left[1+\phi \alpha-\lambda \theta_{2}+(\lambda-\phi \alpha-\lambda \psi) \beta_{2}\right] /[1$ $\left.+\lambda\left(1-\theta_{1}\right)+(\lambda-\phi \alpha-\lambda \psi) \beta_{1}\right]$ that $1-\beta_{1} \pi_{5}-\beta_{2}=\sigma_{z}^{2}\left(\pi_{4}^{2} \sigma_{m}^{2}+\right.$ $\left.\pi_{6}^{2} \sigma_{u}^{2}+\pi_{7}^{2} \sigma_{w}^{2}\right) / \Delta \geqslant 0$ and that $\beta_{2} \geqslant 0$. Therefore, as can be seen from (17) and (18), increases in the economy-wide component of the foreign price shock, $v_{t}$, raise real output relative to its full current information value, while increases in the local component, $z_{t}$, reduce real output relative to its full current information value. That is, real output responds "too much" to aggregate shocks and "not enough" to local (or relative) shocks. The reason for this is that whenever a posi-

in the expressions for $\pi_{4}, \pi_{5}, \pi_{6}$, and $\pi_{7}$. The solutions for these coefficients will then be implicit in the resulting polynomial equations. However, few insights can be gained from this tedious exercise, the results of which are available from the author on request. This difficulty is a general feature of macroeconomic models with differential information such as the one presented here (see, e.g., Barro 1980; King 1982). 
tive aggregate foreign price shock occurs, agents mistakenly perceive part of the change to be the result of a positive local shock, in which case they would like to expand current real output to take advantage of the high local real rate of return. A similar story explains the effects of local shocks. ${ }^{5}$

\section{Effectiveness of Monetary Policy}

A key feature of the model presented here is that the policy rule chosen by the monetary authorities can influence the distribution of real output (and the perceived real rate of return). It can do so because agents have differential information but transact in a common market, and hence there is room for monetary policy to be effective by altering the information content of commonly observed market prices. In this case it is the information content of the exchange rate that can be altered by monetary policy. Insight into this result can be obtained by noting from (11) and the solutions for $\pi_{0}, \pi_{1}, \pi_{2}$, and $\pi_{3}$ that

$$
\overline{E_{z} S_{t+1}}=S_{t}^{0}+\overline{E_{z} m_{t}}+(\psi-1) \overline{E_{z} v_{t}},
$$

where $S_{t}^{0}=\pi_{0}+\pi_{1}\left(M_{t-1}+\psi v_{t-1}\right)+\pi P_{t-1}^{*}$, is that part of the exchange rate that can be predicted on the basis of past information. Substituting this into (9) and rearranging yields

$$
\begin{aligned}
(1+\lambda)\left(S_{t}-S_{t}^{0}\right)= & {\left[m_{t}-(1+\phi \alpha) v_{t}-\phi u_{t}-w_{t}\right] } \\
& +\left\{\lambda \overline{E_{z} m_{t}}+[\phi \alpha+\lambda(\psi-1)] \overline{E_{z} v_{t}}\right\} .
\end{aligned}
$$

Since $S_{t}^{0}$ is known to all agents from their knowledge of the economy's past history, the right-hand side of (19) describes the new information conveyed to agents by the current exchange rate. This new information has two distinct components: the first concerns the combination of aggregate shocks $m_{t}-(1+\phi \alpha) v_{t}-\phi u_{t}-w_{t}$, and the second market expectations as reflected by the term $\lambda \overline{E_{z} m_{t}}+[\phi \alpha+\lambda(\psi-$ 1)] $\overline{E_{z} v_{t}}$. If agents in different markets are differentially informed they will not know the market expectations component of (19), and because of this noise they will form different expectations of the aggre-

\footnotetext{
${ }^{5}$ Aggregate demand for this economy will have the same form as the aggregate supply function obtained by averaging (4) across all markets, except that it will be inversely related to the perceived real rate of return. Therefore, under flexible exchange rates the trade account will respond "too much" to aggregate shocks- the capital account will behave similarly (since the two must add to zero). Furthermore, the model predicts that the trade-account surplus will be positively correlated with real output over the business cycle. Under fixed exchange rates similar results hold for the trade balance, but its movements need not be mirrored by the capital account because of fluctuations in the balance of payments. These remarks assume that wealth effects are small. See Stockman and Koh (1982) for a discussion that includes wealth effects.
} 
gate shocks component, $m_{t}-(1+\phi \alpha) v_{t}-\phi u_{t}-w_{t}$. Monetary policy can alter the distribution of market expectations through its impact on the information content of the exchange rate, which arises because the policy parameter $\psi$ enters the second term of (19). The policy parameter $\psi$ enters (19) and thus influences the information content of the exchange rate, both directly and indirectly, through its effect on the endogenous expectations $\overline{E_{z} m_{t}}$ and $\overline{E_{z} v_{t}}$. Because monetary policy can alter the information content of the exchange rate, it can influence the distribution of real output about its full current information value since this distribution depends on agents' forecast errors. ${ }^{6}$

In the case where there are no local deviations from purchasingpower parity, agents are not differentially informed and local and market expectations are identical (i.e., $E_{z} m_{t}=\overline{E_{z} m_{t}}$, etc.). Therefore, monetary policy cannot alter the distribution of real output since all agents know market expectations and can thus reduce the information content of the exchange rate to its aggregate shocks component, $m_{t}-(1+\phi \alpha) v_{t}-\phi u_{t}-w_{t}$, which is independent of the policy parameter $\psi .^{7}$ However, agents still have incomplete information since they cannot accurately predict the four remaining shocks $\left(m_{t}, u_{t}\right.$, $v_{t}$, and $w_{t}$ ) from the knowledge of the exchange rate and local foreign currency prices, $P_{t}^{*}(z)$. This means that monetary policy does not attain potency simply because agents lack full current information. On the other hand, when local deviations from purchasing-power parity are present, monetary policy is able to influence the distribution of real output. But in this case, agents not only have incomplete information-they also have differential information because, as shown by (14) and (15), the market in which they are currently located colors their view of the state of the economy. The upshot is that monetary policy is able to influence the distribution of real output only to the extent that agents transacting in a common market have incomplete and differential information.

Finally, to see that monetary policy gains its leverage because of its ability to alter the information content of the exchange rate, not of local prices, note that the recursive projection formula implies that

$E_{z} v_{t}=E_{z}\left[v_{t} \mid P_{t}^{*}(z)\right]+E_{z}\left\{v_{t}-E_{z}\left[v_{t} \mid P_{t}^{*}(z)\right] \mid S_{t}-S_{t}^{0}-E_{z}\left[S_{t}-S_{t}^{0} \mid P_{t}^{*}(z)\right]\right\}$,

${ }^{6}$ If the policy rule (7) were extended to include other lagged shocks, the policy parameters attached to them would also influence the distribution of real output. Flood and Hodrick (1982) have shown that feedback on the current exchange rate is irrelevant for the distribution of real output, since it is observed by private agents.

${ }^{7}$ When there are no local deviations from purchasing-power parity $y_{t}(z)=\tilde{y}_{t}(z)$ in the setup adopted here since knowledge of $P_{t}^{*}(z)$ fully reveals $v_{t}$. If foreign prices were subject to both permanent and transitory shocks this extreme result would not hold. 
which follows from the fact that agents observe $P_{t}^{*}(z)$ and $S_{t}-S_{t}^{0}$. It can easily be demonstrated that

$$
E_{z}\left[v_{t} \mid P_{t}^{*}(z)\right]=\gamma\left(v_{t}+z_{t}\right) ; \quad \gamma=\frac{\sigma_{v}^{2}}{\sigma_{v}^{2}+\sigma_{z}^{2}} .
$$

Since the first term of (20) is, therefore, independent of the money supply rule, it follows that monetary policy influences agents' prediction errors, and hence the distribution of real output, because of its ability to influence the information content of the exchange rate as reflected by the second term of (20). This has important implications for the comparison of the variance of real output under fixed and flexible exchange rates that is taken up in Section V. Before turning to this issue, however, the next section will consider the case of a fixed exchange rate regime.

\section{Fixed Exchange Rates}

Under a fixed exchange rate regime, which here means any system in which the exchange rate is set by a feedback rule, the monetary authorities sacrifice control of the money supply in order to manipulate the exchange rate. For simplicity, it is assumed that the monetary authorities set the exchange rate according to the rule

$$
S_{t}=S_{t-1}+\rho v_{t-1},
$$

where $\rho$ is a policy parameter reflecting the extent to which exchange rate changes are used to offset $(\rho<0)$ or reinforce the price-level effects of past foreign price shocks. This particular rule has been chosen to parallel the money supply rule (7) that was used in the discussion of flexible exchange rates. ${ }^{8}$ The rule can easily be generalized to allow for a policy response to other lagged shocks without altering any of the conclusions of this section.

Because the monetary authorities are committed to buy and sell foreign exchange in order to support the exchange rate rule (22), movements in the money supply replace the exchange rate as the mechanism that equilibrates the asset market. From (22) it can be seen that $\overline{E_{z} S_{t+1}}=S_{t}+\rho \overline{E_{z} v_{t}}$, and with this and (22) in the asset market equilibrium condition (9), it can be shown that the money supply must satisfy the condition

$$
\begin{aligned}
M_{t}= & S_{t-1}+\rho v_{t-1}+P_{t-1}^{*}+(1+\phi \alpha) v_{t}+\phi u_{t}+w_{t} \\
& -(\lambda-\phi \alpha) i^{*}-(\phi \alpha+\lambda \rho) \overline{E_{z} v_{t} .}
\end{aligned}
$$

\footnotetext{
${ }^{8}$ No random element comparable to $m_{t}$ is included in (22) since it would be revealed to agents via their observation of the current exchange rate.
} 
Equation (23) can be used to solve for the equilibrium money supply under full current information and incomplete information. However, as before, this is not done explicitly at this point, since it is the behavior of real rather than nominal variables that is of primary concern.

As in the flexible exchange rate case, it is still true that deviations of real variables from their full current information values arise only to the extent that agents make errors in predicting economy-wide foreign price shocks. Therefore, in the case of incomplete information, (16) and (17) continue to hold under fixed exchange rates. To solve for the real equilibrium of the model under incomplete information and a fixed exchange rate, an expression for $E_{z} v_{t}$ is needed. As before, the recursive projection formula implies that this expectation is given by (20). However, since the exchange rate is determined by the feedback rule (22), it follows that $S_{t} \equiv S_{t}^{0}$ and that the second term in (20) is identically zero. Therefore, under a fixed exchange rate regime the conditional expectation of the economy-wide foreign price shock held by agents in market $z$ is given by (21). Substitution of (21) into (16) and (17) gives $r_{t}(z)-\tilde{r}_{t}(z)=(1-\gamma) v_{t}-\gamma z_{t}$ and

$$
y_{t}(z)-\tilde{y}_{t}(z)=\alpha(1-\gamma) v_{t}-\alpha \gamma z_{t} .
$$

As in the flexible exchange rate case, real output responds "too much" to aggregate foreign price shocks and "not enough" to local shocks.

The major implication of (24) is that the exchange rate rule does not affect the distribution of real output even though agents have incomplete and differential information. ${ }^{9}$ The reason for this is that when the exchange rate is a policy variable determined by a feedback rule, the monetary authorities cannot influence its information content. Only to the extent that the exchange rate responds to current conditions, as it does under a flexible exchange rate regime, can policy rules possibly influence the distribution of real output. Fixing the exchange rate by a feedback rule robs the exchange rate of its information content and, for better or worse, deprives the monetary authorities of any power they might otherwise have had to affect the distribution of real output.

\section{A Comparison of Alternative Exchange Rate Regimes}

In a comparison of fixed and flexible exchange rate regimes two major results emerge. These results are presented and then possible qualifications and extensions are discussed.

\footnotetext{
${ }^{9}$ Note that the policy parameter $\rho$ does not appear in (24).
} 


\section{A. The Role of Policy and the Superiority of a Flexible Rate}

The first major result concerns the role of monetary policy under fixed and flexible exchange rates. When the exchange rate is flexible the monetary authorities can alter the distribution of real output by the money supply rule that they choose as shown in Section IIIC. The effectiveness of monetary policy in this case arises from its ability to alter the information content of the exchange rate when agents possess incomplete and differential information. ${ }^{10}$ In contrast, under a fixed exchange rate regime the monetary authorities are powerless. Exchange rate policy cannot influence the distribution of real output since setting the exchange rate by a feedback rule entirely destroys its information content, thus shutting off the channel through which monetary policy gains effectiveness. Therefore, when a small open economy moves away from a flexible exchange rate toward a fixed exchange rate, the monetary authorities lose any ability to influence the distribution of real output: it is not simply the case that monetary policy works through different channels; rather it works in one case and not in the other. This result can be viewed as a rational expectations counterpart to Mundell's (1963) results concerning the effectiveness of monetary policy under fixed and flexible exchange rates.

Second, it can be shown that a flexible exchange rate regime unambiguously results in a smaller variance of real output about its full current information value than does a fixed exchange rate regime. ${ }^{11}$ That is, a small open economy with a fixed exchange rate can reduce the amplitude of its business cycle by adopting a flexible exchange rate. To see this, note from (17) that the variance of real output about its full current information value is directly related to the variance of agents' forecast errors in predicting the economy-wide component of the foreign price shock, $v_{t}$. When the recursive projection formula is applied, this forecast is given by (20). Under both regimes the first term of $(20)$ is given by (21). However, under a fixed exchange rate the second term in (20) is zero, while under flexible exchange rates it is not. This reflects the fact that when the exchange rate is flexible it conveys useful information, but when it is fixed by a feedback rule it does not. Therefore, because a flexible exchange rate provides agents with more information than does a fixed exchange rate, and since more information always improves (or at least does not worsen) fore-

${ }^{10}$ The ability of monetary policy to influence the distribution of real output in the model presented here is in contrast to results derived by Kimbrough (1983a). The difference arises because it is assumed there that all agents possess the same information and hence no differential information exists for policymakers to exploit.

${ }^{11}$ Flood and Hodrick (1982) reach the same conclusion for similar reasons using a different model. 
casting accuracy, it follows that adoption of a flexible exchange rate will result in a smaller variance of real output about its full current information value. In the model presented here, this is true except in the limiting case where the variance of the new information contained in the exchange rate conditional on the information conveyed by the local foreign price, $\operatorname{var}\left[S_{t}-S_{t}^{0} \mid P_{t}^{*}(z)\right]$, approaches infinity, since observing a totally noisy signal provides no information at all. This could be the case if, for instance, the monetary authorities refuse to follow the systematic part of their policy rule very closely and $\sigma_{m}^{2} \rightarrow \infty$. In this case, the variance of real output is the same under the two regimes. Hence one cannot argue that a fixed exchange rate is to be preferred on the grounds that it "disciplines" monetary policy by committing the monetary authorities to peg the exchange rate. Regardless of the wisdom (in the sense of making judicious choices of policy parameters such as $\psi$ ) or discipline with which monetary policy is conducted, for a small open economy the amplitude of the business cycle should be less with a flexible exchange rate than with a fixed exchange rate. ${ }^{12}$ This "superiority" of flexible exchange rates arises solely because of the power of market-determined prices to convey useful information to rational agents - a power that is forfeited when policymakers attempt to fix the exchange rate by a feedback rule. It is important to note that the superiority of flexible exchange rates holds even though money demand shocks influence domestic prices under floating rates (via the exchange rate), while domestic prices are insulated from money demand shocks (of domestic origin) under fixed exchange rates. The reason that this is irrelevant for the relative stability of real output under the two regimes is that a small country takes the real rate of return, $r_{t}(z)$, which matters for output decisions as given. That is, while the two regimes differ in terms of the impact of domestic money demand shocks on nominal prices, intertemporal relative prices in a small country are insulated from domestic money demand shocks under both regimes.

\section{B. Qualifications and Extensions}

There appear to be five important qualifications and possible extensions of the results presented in this paper. These qualifications and extensions take three basic forms-altering the information set,

${ }^{12}$ Of course, wisdom and discipline in the conduct of monetary policy are desirable; the argument here is not to the contrary. The claim is that a small open economy can reduce the amplitude of its business cycle by adopting a flexible exchange rate. Then, having adopted a flexible exchange rate, policymakers can concern themselves with finding the optimal money supply rule. In the context of the model presented here this involves choosing the values for $\psi$ and $\sigma_{m}^{2}$ that minimize the variance of real output about its full current information value. 
changing the specification of the local commodity supply function, and respecifying or extending the markets in which agents are assumed to transact.

The first qualification concerns the information set agents possess. The main extension in this regard is that agents could be assumed to observe monetary aggregates contemporaneously, rather than with a lag as in the present setup. This information could be either exact or noisy, as in King (1981). In either case, the results would be modified in two ways. First, exchange rate policy would be able to affect the distribution of real output by altering the information content of the observed monetary aggregate. This issue is taken up by Kimbrough $(1983 b)$. Second, the "superiority" of a flexible exchange rate regime would be called into question because, although it is still true that the information content of the exchange rate is nil under a fixed exchange rate regime, the information conveyed by observing monetary aggregates might be enough to offset this disadvantage. ${ }^{13}$ One difficulty with this extension, as noted by King (1981), is that if agents observe monetary aggregates contemporaneously, then an econometrician with data on these aggregates should find them to be uncorrelated with real output. However, empirical evidence clearly supports the existence of a positive correlation between money and real output over the course of the business cycle. This extension must, therefore, be reconciled with the empirical evidence before it can be accepted as valid. Another extension in the same spirit would be to assume that agents know their own money holdings, $M_{t}(z)$, rather than the aggregate money supply, $M_{t}$. As shown in an appendix that is available on request, this can be viewed as a special case of noisy information about the aggregate money supply. However, it can also be shown that expanding the information set in this manner does not alter the paper's qualitative conclusions concerning the role of monetary policy under fixed and flexible exchange rates and the "superiority" of flexible exchange rates. In fact, the availability of information about local money holdings actually strengthens the case for flexible exchange rates. ${ }^{14}$

\footnotetext{
${ }^{13}$ To compare fixed and flexible exchange rate regimes in this case simulation methods would be needed to (i) find optimal money supply and exchange rate rules and (ii) compare the stability of real output under the two regimes when the optimal rule is in force. The need for simulation stems from the fact that a closed-form solution to the model is not readily obtained analytically.

${ }^{14}$ Under both fixed and flexible exchange rates, agents observe local foreign currency prices and economy-wide interest rates. Since local money holdings depend on these variables and since foreign prices and interest rates are not influenced by domestic shocks in the small country case, it follows that agents can reduce the information content of local money holdings to a combination of domestic shocks that is uncorrelated with foreign prices and interest rates. Therefore, under fixed exchange rates
} 
A second extension concerns adding a wealth term to the local commodity supply function along the lines of Barro (1980). In this case, monetary discipline (as measured by $\sigma_{m}^{2}$ ) is an important factor in comparing exchange rate regimes (provided that wealth effects are not very weak). It can be shown, however, that as long as monetary policy under flexible exchange rates is not too undisciplined (i.e., as long as $\sigma_{m}^{2}$ is not too large), flexible exchange rates will be superior to fixed exchange rates in stabilizing real output. The results presented earlier can be viewed as being based on the assumption that wealth effects are weak, as reported by Lucas and Rapping (1969).

Yet a third qualification concerns extensions of the model designed to make the country large in some markets. This could be done by making the country large in world markets (say small in its import market and large in its export market) or by introducing into the model nontraded goods or assets that are traded economy wide. With these modifications, exchange rate policy could influence the distribution of real output by altering the information content of an endogenous price other than the exchange rate, so long as that price is observed by all agents. In addition, no unambiguous conclusion regarding the amplitude of the business cycle under fixed and flexible exchange rates would emerge in this case. This result is due to differences in the stochastic structure of the economy under the two regimes, as shown by Kimbrough (1983a). These qualifications serve to highlight the crucial role played by parity conditions in deriving the results presented earlier.

A fourth qualification concerns private indexing based on either local commodity prices or the exchange rate. As shown by King (1982), such indexing schemes are comparable to monetary policy in that they can affect the distribution of real output through their influence on the information content of market prices. Introducing such an indexing scheme into the present setup would have policy implications along the lines suggested by King (1982). However, the superiority of a flexible exchange rate in terms of stabilizing real output would remain intact, since it would still be true that the exchange rate conveys useful information when it is flexible but not when it is fixed.

Finally, it should be noted that the model presented here does not

the information provided by local money holdings will not help agents to forecast $v_{t}$. However, under flexible exchange rates agents have two bits of information, local foreign prices and the exchange rate, that are useful in forming forecasts of $v_{t}$, and the exchange rate is contaminated by various domestic shocks. Hence the availability of local money supply information will improve agents' forecasts of $v$, because they can use the knowledge about domestic shocks it provides to "sharpen" the information about the aggregate foreign price shock, $v_{t}$, conveyed to them by the exchange rate. 
include a forward market in foreign exchange. In Kimbrough (1982) the model is extended in this direction. There, it is shown that the properties of the forward rate as a predictor of the future spot rate are a crucial determinant of the effectiveness or ineffectiveness of monetary and exchange rate policies and of the relative stability of real output under fixed and flexible exchange rates. The omission of a forward market in the present model can be viewed in one of three ways. First, it can be viewed as an assumption that for the currency of the country in question no such market exists, either because of legal or other institutional constraints or simply because the market is "too thin." Second, empirical evidence indicates that movements of spot and forward exchange rates are highly correlated (see Frenkel 1981). This suggests that spot and forward rates convey pretty much the same information. Therefore, as a practical matter, the omission of a forward market may not be too serious. Third, the model presented here can be viewed as making the extreme, but simplifying, assumption that the forward rate is a totally noisy signal and thus conveys no useful information (although empirical evidence would certainly contradict this assumption).

Now that earlier results have been qualified in several respects, it is important to reassess them in the light of these qualifications. Regarding the role of monetary policy under flexible exchange rates, none of the qualifications just noted alters the conclusion that it can influence the distribution of real output so long as agents with incomplete and differential information trade in a common market. However, to the extent that other endogenous variables besides the exchange rate, be they prices or monetary aggregates, are observed by all agents, the conclusion that exchange rate policy is ineffective may no longer hold. Finally, the superiority of a flexible exchange rate in stabilizing real output is subject to some qualifications. However, for a country that is small in world goods markets and whose nontraded goods and assets are close substitutes for traded goods and assets, so that their prices are closely aligned with world prices, adopting a flexible exchange rate is likely to reduce the amplitude of the business cycle (if wealth effects are weak and/or monetary policy is disciplined). This result highlights the role of market-determined prices in facilitating the efficient allocation of scarce resources by conveying useful information to rational agents.

\section{References}

$\rightarrow$ Barro, Robert J. "A Capital Market in an Equilibrium Business Cycle Model." Econometrica 48 (September 1980): 1393-1417.

Flood, Robert P., and Hodrick, Robert J. "Optimal Price and Inventory Ad- 
justment in an Open-Economy Model of the Business Cycle." Unpublished manuscript. Washington: Bd. Governors Fed. Reserve System; and Pittsburgh: Carnegie-Mellon Univ., 1982.

$\rightarrow$ Flood, Robert P., and Marion, Nancy Peregrim. "The Transmission of Disturbances under Alternative Exchange-Rate Regimes with Optimal Indexing." Q.J.E. 97 (February 1982): 43-66.

$\rightarrow$ Frenkel, Jacob A. "Flexible Exchange Rates, Prices, and the Role of 'News': Lessons from the 1970s." J.P.E. 89 (August 1981): 665-705.

Friedman, Milton. "The Role of Monetary Policy." A.E.R. 58 (March 1968): $1-17$.

Harris, Richard G., and Purvis, Douglas D. "Diverse Information and Market Efficiency in a Monetary Model of the Exchange Rate.” Econ.J. 91 (December 1981): 829-47.

Kimbrough, Kent P. "The Forward Rate as a Predictor of the Future Spot Rate, the Role of Policy, and Exchange Rate Regime Choice." Unpublished manuscript. Durham, N.C.: Duke Univ., 1982.

- "The Information Content of the Exchange Rate and the Stability of Real Output under Alternative Exchange Rate Regimes." J. Internat. Money and Finance 2 (April 1983): 27-38. (a)

- "Exchange Rate Policy and Monetary Information."J. Internat. Money and Finance 2 (December 1983): 333-46. (b)

King, Robert G. "Monetary Information and Monetary Neutrality." J. Monetary Econ. 7 (March 1981): 195-206.

$\longrightarrow \rightarrow$-. "Monetary Policy and the Information Content of Prices." J.P.E. 90 (April 1982): 247-79.

- "Interest Rates, Aggregate Information, and Monetary Policy." J. Monetary Econ. 12 (August 1983): 199-234.

Lucas, Robert E., Jr. "Expectations and the Neutrality of Money." J. Econ. Theory 4 (April 1972): 103-24.

- "Some International Evidence on Output-Inflation Tradeoffs." A.E.R. 63 (June 1973): 326-34.

$\rightarrow$ Lucas, Robert E., Jr., and Rapping, Leonard A. "Real Wages, Employment, and Inflation." J.P.E. 77 (September/October 1969): 721-54.

$\rightarrow$ Mundell, Robert A. "Capital Mobility and Stabilization Policy under Fixed and Flexible Exchange Rates." Canadian J. Econ. and Pol. Sci. 29 (November 1963): 475-85.

Phelps, Edmund S. "The New Microeconomics in Employment and Inflation Theory." In Microeconomic Foundations of Employment and Inflation Theory, edited by Edmund S. Phelps et al. New York: Norton, 1970.

$\rightarrow$ Sargent, Thomas J., and Wallace, Neil. "Rational Expectations, the Optimal Monetary Instrument, and the Optimal Money Supply Rule.” J.P.E. 83 (April 1975): 241-54.

Stockman, Alan C., and Koh, Ai Tee. "Models of Business Fluctuations in Open Economies.” Unpublished manuscript. Rochester, N.Y.: Univ. Rochester, 1982.

$\rightarrow$ Weiss, Laurence. "The Role for Active Monetary Policy in a Rational Expectations Model.” J.P.E. 88 (April 1980): 221-33.

1982): $31-42$. 